\title{
THE ULTRA-VIOLET ABSORPTION OF SEA WATER
}

\author{
By F. A. J. Armstrong and G. T. Boalch
}

The Plymouth Laboratory

\section{(Text-figs. I-3)}

The intensity of submarine daylight is of such importance to the growth of marine plants that much attention has been given to measurements of the absorption of solar radiation by sea water. It has long been known that absorption is least in the blue green in the visible spectrum, and Tsukamoto (I927) showed that the absorption of ultra-violet radiation increased very steeply between 300 and $200 \mathrm{~m} \mu$. Kalle (1937) showed that absorption in the blue increased in coastal waters, and ascribed the effect to increased absorption of indeterminate organic materials which he thought to be similar to the 'humic acids' of river and lake waters, and which he named 'Gelbstoff'. Joseph (I949) used a submersible photometer and was able to extend measurements to about $367 \mathrm{~m} \mu$, just outside the visible region, and showed that the absorption of 'coastal' waters was enhanced at this wave-length. Baltic Sea water of low salinity was in fact much less transparent than water from the North Sea. Jerlov (1950) further extended measurements to $310 \mathrm{~m} \mu$ and revealed even greater differences between different sea waters. In the eastern Mediterranean for example, where the water was of clarity comparable with that of the Sargasso Sea, the loss per metre at $310 \mathrm{~m} \mu$ was $14 \%$, compared with $90 \%$ in the Skagerrak. At $375 \mathrm{~m} \mu$ the eastern Mediterranean water absorbed only $5 \%$ per metre so that in such clear water biologically important radiation might, in his opinion, penetrate to about $20 \mathrm{~m}$. Jerlov (I95I) showed that a considerable range of sea waters could be classified by comparison of their absorption spectra, the distinctions being greatest at short wave-lengths. Scattering by particulate matter contributed materially to the attenuation of the light beam in Jerlov's underwater apparatus and was appreciable at the shorter wave-lengths. Lenoble (1956b) has measured the in situ absorption of ultra-violet radiation down to $318.5 \mathrm{~m} \mu$, at various stations in the Mediterranean, and has also (1956 a) measured the absorptions between wave-lengths of 250 and $400 \mathrm{~m} \mu$, of solutions of the salts which may be used to constitute artificial sea water.

On repeating these latter measurements of Lenoble, and extending them to $200 \mathrm{~m} \mu$, we have found a big difference between the absorption of sea water and that of its component salts, confirming a finding by Chanu (I959). 
We considered therefore that further study might be interesting both as a measure of a physical property characterizing different sea waters and as a guide to their chemical composition.

We are grateful to the Director and staff of the National Institute of Oceanography for allowing one of us (F.A.J.A.) to collect samples from R.R.S. 'Discovery II', and to Mr E. I. Butler for help in collecting samples. One of us (G.T.B.) holds an International Paints Research Fellowship and his thanks are due to $\mathrm{Mr} \mathrm{O}$. D. Hunt for permission to engage in this work.

\section{APPARATUS AND METHODS}

Measurements were made, usually at intervals of $10 \mathrm{~m} \mu$, between 200 and $400 \mathrm{~m} \mu$ with a Unicam S.P. 500 spectrophotometer and are recorded as the instrument readings of extinction values. Properly, the quantity measured is Absorbancy $(A s)$, where $A s=\log _{10} I_{0} / I, I_{0}$ and $I$ being the intensities of the light beam entering and leaving the cuvette containing the sample. A $10 \mathrm{~cm}$ cuvette with silica windows was used and, to avoid doubt as to the purity and consistency of a liquid medium, all measurements were made with air as the reference path. There is therefore a small correction necessary for loss of light by reflexion at the end windows. An approximate direct measurement gave this as about 0.06 at $200 \mathrm{~m} \mu$ decreasing to 0.03 at $400 \mathrm{~m} \mu$, these values should be subtracted from the measurements reported.

The observations must be regarded as relative, as indeed must most spectrophotometric measurements (Ewing \& Parsons, 1948; Goldring, Hawes, Hare, Beckman \& Stickney, 1953). We know that below $230 \mathrm{~m} \mu$ our measured absorbancies are low. The instrument is an early model with natural quartz optics and the hydrogen discharge lamp had lost some emission, requiring slit widths greater than $\mathrm{I} \mathrm{mm}$. These shortcomings, by broadening the effective band width and decreasing the short wave-length intensities relative to that of scattered light, combine to give low readings particularly when, as here, the sample absorbancy is high. It is difficult to measure such errors directly, but we have been able (using sodium nitrite solutions of approximately unit absorbancy) to compare our instrument with a new one with synthetic quartz optics. The absorbancies on the older instrument, at 200, 210, 220 and $230 \mathrm{~m} \mu$ were respectively $40,80,85$ and $95 \%$ of those found on the new one. The sharp loss below 2 IO $\mathrm{m} \mu$ has caused a spurious maximum to appear at this wave-length in some of the curves, but having drawn attention to this we think it preferable to present our observations with no attempt to apply what would in any case be arbitrary corrections. The errors of the instrument seem to have altered very little in the course of the experiments since slit widths for given sensitivity at short wave-lengths have increased by only about $5 \%$.

Glassware was acid cleaned and well washed with distilled water before use. Water for spectrophotometric measurement and for making artificial sea water was twice distilled in glass (the second time over alkaline permanganate) and then passed through a column of active charcoal (Messrs Sutcliffe Speakman's Grade 315). Further attempts at purification failed to reduce the ultra-violet absorption of this water, which was assumed to contain a negligible amount of impurities.

The artificial sea water was made from analytical grade reagents to the hypothetical formula of Lyman \& Fleming (I940). The sodium chloride and sulphate (the major constituents), and the potassium chloride were heated to redness before use to destroy organic impurities. The other salts would have decomposed on heating. 
Sea-water samples were collected in either 251 . glass carboys or 10 1. Pyrex bottles and were usually filtered within $36 \mathrm{~h}$ through well washed membrane filters or porcelain candles of average pore diameter I $\mu$. Experience with these filtration methods has shown that the amount of particulate matter passing the filters is small (usually less than $0.1 \mathrm{mg} / \mathrm{l}$.) and that the filtrates are comparable as regards Tyndall effect with water freshly distilled and collected with precautions against dust (Armstrong \& Atkins, 1950; Armstrong, 1958).

We think that the contribution of light scattering by particles to the absorbancy of these filtered samples is negligible.

\section{RESULTS}

The absorption spectra of purified water, artificial sea water, and a fairly typical sample of English Channel surface water are shown in Fig. I. Below about $240 \mathrm{~m} \mu$, about half the absorbancy of this natural sea water is accounted for by the inorganic constituents.

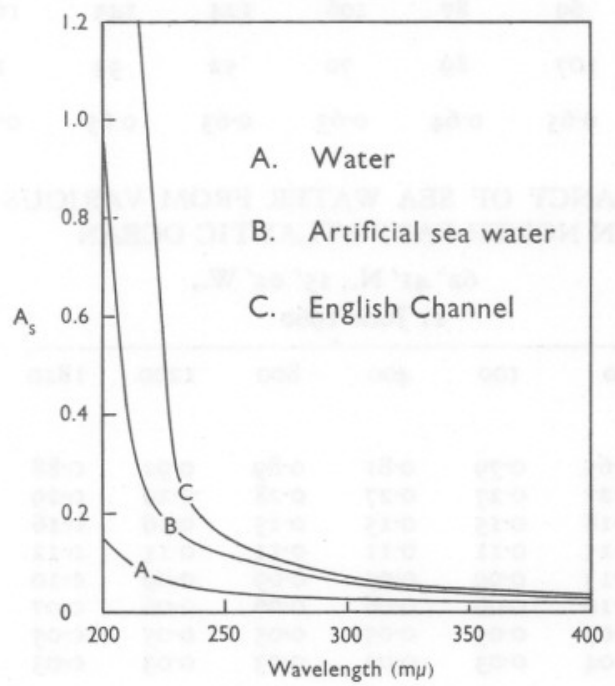

Fig. I

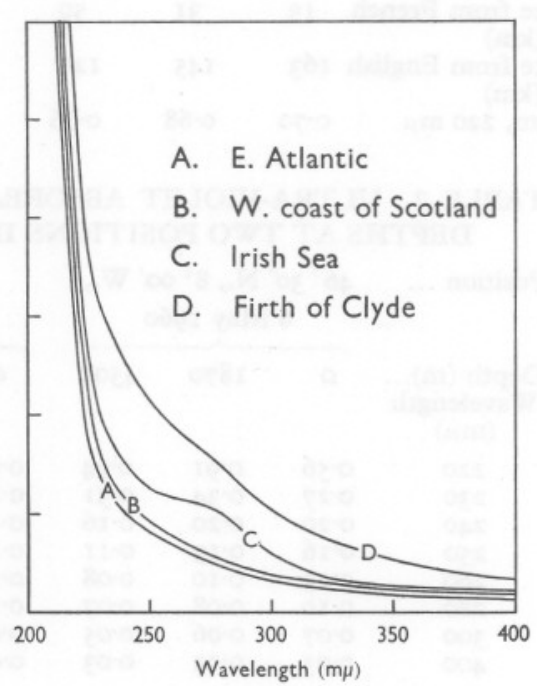

Fig. 2

Fig. I (left). Absorbancy against air. A, purified water; B, artificial sea water; c, English Channel surface water.

Fig. 2 (right). Absorbancy against air. A, $46^{\circ} 30^{\prime}$ N., $8^{\circ} 00^{\prime}$ W., May 1960. B, $58^{\circ}$ ro $0^{\prime}$ N., $8^{\circ} 33^{\prime}$ W., June 1960. C, $54^{\circ} 28^{\prime}$ N., $5^{\circ} 22^{\prime}$ W., June r96o. D, $55^{\circ} 45^{\prime}$ N., $4^{\circ} 54^{\prime}$ W., April I960.

Marked differences were found between sea-water samples of different origin, greater absorbancies being observed in coastal waters. This is shown in Fig. 2, in which three surface samples of coastal waters are compared with one from the north-east Atlantic. The high absorbancy of the Clyde water is very striking. The sample was taken in April at the time of a heavy diatom 
outburst and the filtered water, viewed in a $50 \mathrm{~cm}$ column, was visibly yellow. A good example of the geographical variation is given by the figures of Table $I$. Samples were taken at Io-mile intervals on the $4^{\circ} \mathrm{W}$. meridian, in the English Channel between the French and English coasts, and absorbancies recorded, at $220 \mathrm{~m} \mu$. The increases near the coasts are well marked.

Ultra-violet absorption has been found to vary with depth, and Table 2 gives measurements on samples from various depths at stations in the northeast Atlantic Ocean. The surface samples have relatively greater absorbancies above $235 \mathrm{~m} \mu$, and the deep water samples greater values below this wavelength.

TABLE 1. ULTRA-VIOLET ABSORBANCY OF SEA WATER FROM $10 \mathrm{M}$ DEPTH AT POSITIONS ON $4^{\circ} \mathrm{W}$. MERIDIAN ACROSS ENGLISH CHANNEL 22 FEBRUARY 1961

\begin{tabular}{|c|c|c|c|c|c|c|c|c|c|}
\hline Latitude (N.) & $48^{\circ} 50^{\prime}$ & $49^{\circ} \mathrm{o0^{ \prime }}$ & $49^{\circ}$ Io' & $49^{\circ} 20^{\prime}$ & $49^{\circ} 30^{\prime}$ & $49^{\circ} 40^{\prime}$ & $49^{\circ} 50^{\prime}$ & $50^{\circ} 00^{\prime}$ & $50^{\circ} \mathrm{I}$ \\
\hline $\begin{array}{l}\text { cee from French } \\
(\mathrm{km})\end{array}$ & 13 & $3 \mathrm{I}$ & 50 & 69 & 87 & 106 & I 24 & I43 & I6I \\
\hline $\begin{array}{l}\text { Distance from English } \\
\text { coast }(\mathrm{km})\end{array}$ & 163 & I45 & 126 & 107 & 89 & 70 & 52 & 33 & I5 \\
\hline$A_{s} \mathrm{IO} \mathrm{cm}, 220 \mathrm{~m} \mu$ & $0 \cdot 70$ & 0.68 & 0.66 & 0.65 & 0.64 & 0.63 & 0.63 & 0.65 & 0.74 \\
\hline
\end{tabular}

TABLE 2. ULTRA-VIOLET ABSORBANCY OF SEA WATER FROM VARIOUS DEPTHS AT TWO POSITIONS IN NORTH-EAST ATLANTIC OCEAN

\begin{tabular}{|c|c|c|c|c|c|c|c|c|c|}
\hline \multirow{2}{*}{$\begin{array}{l}\text { Position ... } \\
\begin{array}{l}\text { Depth (m)... } \\
\text { Wavelength } \\
\qquad(\mathrm{m} \mu)\end{array}\end{array}$} & \multicolumn{3}{|c|}{$\begin{array}{c}46^{\circ} 30^{\prime} \text { N., } 8^{\circ} 00^{\prime} \text { W., } \\
6 \text { May I } 960\end{array}$} & \multicolumn{5}{|c|}{$\begin{array}{l}62^{\circ} 4 \mathrm{I}^{\prime} \text { N., } 15^{\circ} 02^{\prime} \mathrm{W} . \\
\text { II June I960 }\end{array}$} & \multirow{2}{*}{$\mathrm{I}_{1810}$} \\
\hline & 0 & I 870 & 4500 & 0 & 100 & 400 & 800 & 1200 & \\
\hline 220 & 0.56 & 0.91 & 0.94 & 0.65 & 0.79 & $0.8 \mathrm{I}$ & 0.89 & 0.92 & 0.88 \\
\hline 230 & 0.27 & 0.34 & 0.31 & 0.27 & 0.27 & 0.27 & 0.28 & 0.29 & 0.29 \\
\hline 240 & 0.20 & 0.20 & 0.16 & 0.18 & 0.15 & 0.15 & 0.15 & 0.16 & 0.16 \\
\hline 250 & 0.16 & 0.13 & $0.1 I$ & 0.15 & 0.11 & O.II & $0.1 \mathrm{I}$ & $0.1 \mathrm{I}$ & 0.12 \\
\hline 260 & 0.13 & 0.10 & 0.08 & 0.13 & 0.09 & 0.09 & 0.09 & 0.09 & 0.10 \\
\hline 280 & 0.10 & 0.08 & 0.07 & 0.10 & 0.06 & 0.06 & 0.06 & 0.06 & 0.07 \\
\hline 300 & 0.07 & 0.06 & 0.05 & 0.07 & 0.05 & 0.05 & 0.05 & 0.05 & 0.05 \\
\hline 400 & 0.03 & 0.03 & 0.03 & 0.04 & 0.03 & 0.03 & 0.03 & 0.03 & 0.03 \\
\hline
\end{tabular}

Surface, Io and $50 \mathrm{~m}$ samples from a position in the English Channel were examined monthly during the period April I959 to November 1960, and the absorbancies at 220 and $250 \mathrm{~m} \mu$ are shown in Fig. 3. There are considerable irregularities and perhaps a slight increase in summer. Higher absorbancies often coincided with the small decreases in salinity and increases in silicate which indicate increased admixture of land drainage water. There was a slight tendency for the upper samples to have higher absorbancies than the deeper ones. 


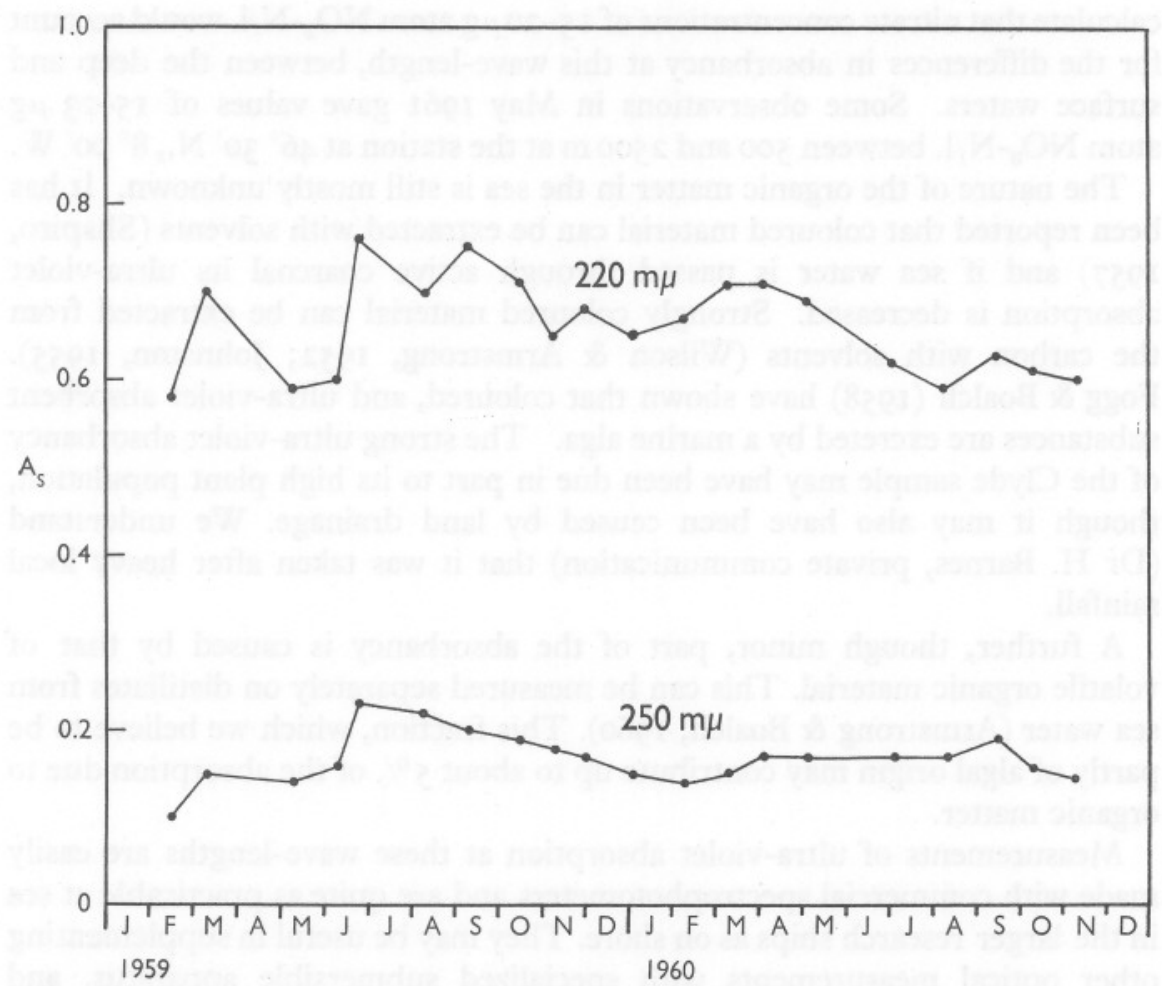

Fig. 3. Seasonal change in absorbancy at two wave-lengths, International Hydrographic Station E I ( $50^{\circ} 02^{\prime}$ N., $4^{\circ} 22^{\prime}$ W.).

\section{DISCUSSION}

The results indicate that the increase in absorption at the blue end of the spectrum shown by Kalle to be characteristic of coastal waters, and confirmed by Joseph at $367 \mathrm{~m} \mu$ and by Jerlov at $310 \mathrm{~m} \mu$, becomes even more marked below $300 \mathrm{~m} \mu$. The great difference between artificial and natural sea waters suggests that much of the ultra-violet absorption must be due to organic matter and it is reasonable to suppose that what is being measured is, at least in part, the absorbancy of Kalle's 'Gelbstoff' at short wave-lengths. This does not explain the change in character of the absorption spectra with increased depth in the north-east Atlantic and an interpretation is needed of the observations in the deep water samples, of lower absorbancy above $235 \mathrm{~m} \mu$ and higher absorbancy below this wave-length. The former may be due, perhaps, to the differing origin and age of the deep water, and the latter effect may be ascribed to its higher nitrate concentration. Nitrate ion absorbs strongly in the short ultra-violet, with a maximum at about $203 \mathrm{~m} \mu$ (Bastin, Weberling \& Palilla, 1957). We find that its absorption at $220 \mathrm{~m} \mu$ is considerable, and 
calculate that nitrate concentrations of $15-20 \mu \mathrm{g}$ atom $\mathrm{NO}_{3}-\mathrm{N} / 1$. would account for the differences in absorbancy at this wave-length, between the deep and surface waters. Some observations in May 196I gave values of $15-23 \mu \mathrm{g}$ atom $\mathrm{NO}_{3}-\mathrm{N} / 1$. between 500 and $2500 \mathrm{~m}$ at the station at $46^{\circ} 30^{\prime} \mathrm{N} ., 8^{\circ} 00^{\prime} \mathrm{W}$.

The nature of the organic matter in the sea is still mostly unknown. It has been reported that coloured material can be extracted with solvents (Shapiro, 1957) and if sea water is passed through active charcoal its ultra-violet absorption is decreased. Strongly coloured material can be extracted from the carbon with solvents (Wilson \& Armstrong, 1952; Johnston, 1955). Fogg \& Boalch (1958) have shown that coloured, and ultra-violet absorbent substances are excreted by a marine alga. The strong ultra-violet absorbancy of the Clyde sample may have been due in part to its high plant population, though it may also have been caused by land drainage. We understand (Dr H. Barnes, private communication) that it was taken after heavy local rainfall.

A further, though minor, part of the absorbancy is caused by that of volatile organic material. This can be measured separately on distillates from sea water (Armstrong \& Boalch, 1960). This fraction, which we believe to be partly of algal origin may contribute up to about $5 \%$ of the absorption due to organic matter.

Measurements of ultra-violet absorption at these wave-lengths are easily made with commercial spectrophotometers and are quite as practicable at sea in the larger research ships as on shore. They may be useful in supplementing other optical measurements with specialized submersible apparatus, and should help in the physical classification of water masses, and possibly give some information on their chemical properties.

\section{SUMMARY}

Measurements of the ultra-violet absorption spectra between 200 and $400 \mathrm{~m} \mu$ have been made with a spectrophotometer. At short wave-lengths natural sea water has double the absorbancy of artificial sea water. The difference in samples from shallow depths is ascribed to organic material, of which part may be the 'Gelbstoff' of Kalle. Regional variations have been found, coastal waters having higher U.V. absorptions. A small seasonal effect with an increase in absorbancy in summer in the English Channel has been seen. In deep Atlantic water increased absorption below $235 \mathrm{~m} \mu$ may be due to its high nitrate concentration. At longer wave-lengths absorbancies were less than in surface waters. Measurements of U.V. absorption may supplement other physical methods of characterizing water masses. 


\section{REFERENCES}

Armstrong, F. A. J., 1958. Inorganic suspended matter in sea water. F. mar. Res., Vol. 17, pp. 23-34.

Armstrong, F. A. J. \& Atkins, W. R. G., 1950. The suspended matter of sea water. F. mar. biol. Ass. U.K., Vol. 29, pp. 139-43.

ARMSTRONG, F. A. J. \& BOALCH, G. T., I960. Volatile organic matter in algal culture media and sea water. Nature, Lond., Vol. 185, pp. 76I-2.

Bastin, R., Weberling, T. \& Palilla, F., 1957. Ultraviolet spectrophotometric determination of nitrate. Analyt. Chem., Vol. 29, pp. 1795-7.

Chanu, J., 1959. Extraction de la substance jaune dans les eaux cotieres. Rev. Opt. (théor. instrum.), T. 38, pp. 569-72.

EWING, G. W. \& Parsons, T., I948. Intercomparison of Beckman spectrophotometers. Analyt. Chem., Vol. 20, pp. 423-5.

FoGG, G. E. \& BoALCH, G. T., I958. Extracellular products of marine algae. Nature, Lond., Vol. I8I, pp. 789-90.

Goldring, L. S., Hawes, C. R., Hare, G. H., Beckman, A. O. \& Stickney, M. E., 1953. Anomalies in extinction coefficient measurements. Analyt. Chem., Vol. 25, pp. 869-78.

JerLov, N. G., 1950. Ultraviolet radiation in the sea. Nature, Lond., Vol. 166, p. III.

_ I951. Optical studies of ocean waters. Rep. Swed. Deep-sea Exped., 1947-48, Vol. 173, No. I, 59 pp.

JosePH, J., 1949. Durchsichtigkeitsmessungen im Meere im ultravioletten Spektralbereich. Dtsch. hydrogr. Z., Bd. 2, 5, pp. 212-18.

Johnston, R., I955. Biologically active compounds in the sea. F. mar. biol. Ass. U.K., Vol. 34, pp. 185-95.

Kalle, K., 1937. Meereskundliche chemische Untersuchungen mit Hilfe des Zeisschen Pulfrich Photometers. Ann. Hydrogr., Berl., Bd. 65, pp. 276-82.

Lenoble, J., 1956a. Sur le role des principaux sels dans l'absorption ultraviolette de l'eau de mer. C.R. Acad. Sci., Paris, T. 242, pp. 806-8.

I $1956 \mathrm{~b}$. Sur la penetration du rayonnement ultraviolet dans les eaux mediterranéenes. C.R. Acad. Sci., Paris, T. 243, pp. I78I-3.

Lyman, J. \& Fleming, T., I940. Composition of sea water. F. mar. Res., Vol. 3, pp. 134-46.

SHAPIRO, J., 1957. Chemical and biological studies of the yellow organic acids of lake water. Limnol. \& Oceanogr., Vol. 2, pp. 16I-79.

Tsuкамото, K., I927. Transparence de l'eau de mer pour l'ultraviolet lointain. C.R. Acad. Sci., Paris, T. 184, pp. $22 \mathrm{I}-3$.

Wilson, D. P. \& ARmstrong, F. A. J., I952. Further experiments on biological differences between natural sea waters. F. mar. biol. Ass. U.K., Vol. 31, pp. 33549 . 